\title{
Validation of cross-sectional studies with longitudinal meta-analysis
}

\author{
C. Cure-Cure ${ }^{1} \cdot$ P. Cure Cun $^{2,3}$
}

Received: 11 February 2016 / Accepted: 22 March 2016/Published online: 25 April 2016

(C) International Osteoporosis Foundation and National Osteoporosis Foundation 2016

\section{Dear Editor,}

In a meta-analysis of 10 articles that included 217,295 participants and 26,525 cases of osteoporotic fractures (OF), Wang et al. [1] found that women with one or more live births had a lower risk of hip fractures (HP) compared to nulliparous women. The pooled RR of OF were 0.89 (95\% CI 0.85-0.94) for one live birth, 0.81 (95\% CI 0.74-0.89) for two live births, 0.78 ( $95 \%$ CI $0.71-0.85$ ) for three live births, 0.76 (95 \% CI 0.69 0.84 ) for four live births, 0.75 (95\% CI $0.67-0.84$ ) for five live births, and 0.84 (95\% CI 0.64-0.85) for six live births when compared to nulliparous women. This meta-analysis coincides with our findings in a cross-sectional retrospective study in a large population of postmenopausal women from Barranquilla, Colombia, where we found a similar lower risk of fracture in multiparous when compared to nulliparous women, with a pooled RR of OF of 0.81 (95\% CI 0.32-2.05) for one, 0.45 (95\% CI 0.19-1.03) for two, 0.40 (95\% CI 0.24-0.88) for three, 0.55 (95\% CI 0.3-1.02) for four, and 0.52 (95\% CI $0.31-0.88$ ) for five or more live births [2]. In our study, we also found that the bone mineral density and total bone and calcium contents increased as the number of deliveries increased which could be considered a "gestational bone mass peak" analogous to the bone mass peak observed during puberty [3]. The vali-

A response to these comments can be found at doi: 10.1007/s00198-016$3589-4$.

\section{P. Cure}

pablocure@icloud.com

1 Biomelab, Ltda, Barranquilla, Atlántico, Colombia

2 Children's National Health System, 111 Michigan Avenue, NW Washington, DC 20010, USA

3 The George Washington University, Washington, DC, USA dation of cross-sectional studies with long-term longitudinal studies has been documented [4] and can be confirmed here. The similarities in our results with the results obtained by Wang et al. highlight the importance of well-designed cross-sectional studies as an early, reliable, and cost-effective source of information. Of further interest would be to analyze similar crosssectional studies in a meta-analysis and compare those results with the results of this longitudinal meta-analysis.

\section{Compliance with ethical standards}

Conflicts of interest None.

\section{References}

1. Wang Q, Huang Q, Zeng Y, Liang J-J, Liu S-Y, Gu X, Liu J-A (2016) Parity and osteoporotic fracture risk in postmenopausal women: a dose-response meta-analysis of prospective studies. OsteoporosInt 27:319-330. doi:10.1007/s00198-015-3351-3

2. Cure-Cure C, Cure-Ramirez P (2001) Hormone replacement therapy for bone protection in multiparous women: when to initiate it. Am J Obstet Gynecol 184(4):580-583

3. Cure-Cure C, Cure-Ramirez P, Teran E, Lopez-Jaramillo P (2002) Bone-mass peak in multiparity and reduced risk of bone fractures in menopause. Int J Gynaecol Obstet 76(3):285-291

4. Cure-Cure C, Cure P (2012) Validation of cross-sectional studies with long-term longitudinal studies. Osteoporos Int 23:399 